\title{
History, development and future of cancer screening in Australia
}

\author{
Ian N Olver ${ }^{a, c}$ and David Roder ${ }^{b}$ \\ a Sansom Institute for Health Research, University of South Australia, Adelaide \\ ${ }^{b}$ Cancer Epidemiology and Population Health, University of South Australia, Adelaide \\ c Corresponding author: ian.olver@unisa.edu.au
}

\section{Article history}

Publication date: July 2017

Olver IN, Roder D. History, development and future of cancer screening in Australia. Public Health Res Pract. 2017;27(3):e2731725. https://doi.org/10.17061/phrp2731725

\section{Key points}

- The focus of Australia's three population screening programs should be to increase the participation rate of eligible people to maximise the reduction in mortality

- Those eligible for screening must understand the potential adverse consequences, such as overdiagnosis, and balance them against the mortality benefit

- Genomic testing will allow customised screening in the future

\section{Abstract}

Introduction: The aim of screening an asymptomatic population for cancer is to achieve better health outcomes, particularly a population survival benefit. Australia has three population screening programs: the National Cervical Screening Program (NCSP), BreastScreen Australia and the National Bowel Cancer Screening Program (NBCSP).

Methods: We reviewed the history and development of the three programs.

NCSP: Women have a Pap smear every 2 years from age 18-20, or 2 years after first becoming sexually active, until age 69. Since introduction of the NCSP, the cervical cancer incidence has halved, with an approximate $60 \%$ decrease in mortality. The screening participation rate approximates 57\%, but is lower for Aboriginal and Torres Strait Islander women, women in remote areas, and women with lower socio-economic status. The National HPV (human papillomavirus) Vaccination Program, introduced in 2007, is expected to reduce the incidence of cervical cancer by a further $70 \%$ and has already reduced the incidence of highgrade lesions in girls. In 2017, testing for HPV every 5 years starting at age 25 will replace the Pap smear as the principal screening test.

BreastScreen Australia: This program targets women aged 50-74. Over 20 years, mortality from breast cancer has decreased by $32 \%$ in response to screening and treatment advances. The participation rate is $56 \%$. The major adverse impact of breast screening is overdiagnosis, estimated in Australia to be as low as $8 \%$ of detected cancers, but with estimates of up to $30 \%$ from some research. Women should be made aware of both the potential benefits and harms from screening. Genetic testing for BRCA1 and BRCA2 mutations in highrisk women leads to earlier screening.

NBCSP: The NBCSP uses immunochemical faecal occult blood test (iFOBT) kits on stool samples to detect bleeding from the bowel. When rollout is complete in 2020 , test kits will be sent every 2 years to people aged 50-74. People who test positive are followed up with a colonoscopy. The participation rate is currently $37 \%$. The positivity rate is $7 \%$, and stage 1 bowel cancer presentations have tripled since the program began.

Conclusions: Research needs to focus on reducing mortality through increased screening participation and, in the future, obtaining guidance for customised screening from genomic testing. 


\section{Introduction}

The aim of screening an asymptomatic population for cancer is to improve health outcomes by detecting conditions that are associated with elevated cancer risk, or early-stage cancers where treatment will be more effective. The test must be economically feasible, be acceptable to the target population and have potential benefits that outweight the risks. The effectiveness of screening is ultimately determined by whether there is a population survival benefit, which can be assessed using clinical and population-based cancer registry and screening data. ${ }^{1}$

Australia has three population screening programs. Following ad hoc cervical screening since the 1960s, the National Cervical Screening Program (NCSP) started in 1991; mammographic screening for breast cancer was introduced between 1991 and 1995; and the National Bowel Cancer Screening Program (NBCSP) was introduced in 2006, with a goal of being fully implemented by July 2020. ${ }^{2-4}$

We report relative risks in this paper because they can be generally applied across different population subgroups and are therefore useful as summary estimates. When considering the merits of screening specific populations, it is worthwhile to convert to absolute risk.

\section{Screening for cervical cancer}

The NCSP offers a Papanicolaou (Pap) smear every 2 years to women aged 18-20, or 2 years after first becoming sexually active, until age 69 . It has been a very effective program that has approximately halved the incidence of cervical cancer in Australia from approximately 13 cases per 100000 women in 1991 to 7 cases per 100000 women in 2002, where it has now stabilised. The death rate has dropped to 2 per 100 000.5,6

The participation rate in the screening program in 2014 was $57 \%$ of those in the target group, and the 3 -year participation rate was $70 \%$, which demonstrates that women are being screened, but not with the recommended frequency. ${ }^{2}$ However, other countries such as the US recommend a 3-year interval between Pap smears ${ }^{7}$ because there is little impact on survival from more frequent screening.

The participation rate is not uniform across the Australian population. Aboriginal and Torres Strait Islander women have 2-4 times the incidence and mortality rates of cervical cancer as other Australian women. ${ }^{8,9}$ They have lower participation in screening, and a data-linkage study in Queensland has shown higher prevalence of cervical abnormalities in those who are screened..$^{10,11}$

The cervical screening program has been, and will be, affected by advances in the understanding of the aetiology of cervical cancer and its relationship with human papillomavirus (HPV) infection, and technological advances. Liquid-based cytology has replaced conventional cytology in several countries, including England, the US and New Zealand. Its benefits include fewer unsatisfactory specimens, and fewer repeat cytology and other tests, particularly because HPV testing can be conducted on the sample. Liquid cytology has a similar sensitivity to conventional cytology. Its use in Australia was evaluated in 2001 and 2009, but was rejected for public funding on cost-effectiveness grounds, until finally gaining acceptance in 2017. Before acceptance, it was available as an adjunct test to those who could pay for it, and its uptake was dependent on socio-economic status, remoteness and screening history. ${ }^{12}$

The National HPV Vaccination Program, introduced in 2007, will make a significant impact on the incidence and mortality of cervical cancer, which results from chronic HPV infection. The vaccination program was initially introduced in Australia for girls aged 12 years, with a catch-up program for women aged up to 26. Between 2007 and 2009, 72\% of girls aged 14-15 received three doses of a quadrivalent vaccine over 6 months. ${ }^{13}$ In 2013, the program was extended to cover both boys and girls aged 12-13.

HPV types 16 and 18 are responsible for $70 \%$ of cervical cancers. ${ }^{14}$ Ten years of reporting across the world showed a reduction of $90 \%$ for HPV types $6,11,16$ and 18; $85 \%$ for high-grade cervical abnormalities; and 45\% for low-grade abnormalities. ${ }^{15}$ Early data from the Victorian Cervical Cytology Registry showed a decrease in highgrade cervical abnormalities in girls younger than 18 years within 30 months of the introduction of the vaccine. National monitoring is ongoing. ${ }^{16}$

Screening communication emphasises that cervical screening is still necessary for vaccinated women, because not all HPV types that can lead to cervical cancer are covered by the vaccine. In future, vaccines will prevent an even broader spectrum of HPV types, increasing the percentage of cervical cancer that could be prevented. ${ }^{17}$

Because of the causal association of persisting infection with a high-risk strain of HPV with development of cervical cancer, testing for the presence of HPV DNA identifies women at risk of developing high-grade lesions. International randomised trials comparing HPV DNA testing with cytology for primary screening have shown HPV testing to be superior. ${ }^{18}$ A current trial is comparing HPV tests every 5 years with Pap smears every 2.5 years, covering both HPV-vaccinated and nonvaccinated age ranges, to check these results in Australian clinical settings. ${ }^{19}$

The increasing percentage of women being vaccinated was one reason for changing the NCSP. Towards the end of 2017, an HPV test will replace conventional cytology in the NCSP. Women will be tested every 5 years starting at 25 years of age, with an exit test at age $70-74 .{ }^{20}$ For HPVpositive women, liquid-based cytology will be performed on the sample. The challenge is to make the change to the program while maintaining a high screening rate in eligible women. 


\section{Screening for breast cancer}

The BreastScreen Australia program was introduced between 1991 and 1995, targeting women aged 50-69 as the group most likely to benefit. It was extended to the 70-74-year-old age group in 2013. There was an initial pronounced rise in the incidence of breast cancer because of the detection of earlier lesions, but that stabilised once the program was fully established, and any further increases in incidence should be attributed to other causes. Over the 20 years since implementation of the program, breast cancer mortality has decreased at a population level (all ages) by about 32\%.21-23 Some of this would be due to improvements in treatment, and some to early detection from screening. Modelling of US data suggested that half of the improvement in that country would be due to screening. ${ }^{24}$

The national BreastScreen evaluation recorded participation at 56\%. From national and jurisdictional evaluations, it estimated that 8 deaths would be prevented for every 1000 women screened in the target group of 50-74-year-olds. ${ }^{25-29}$ The potential benefit varies depending on the age range being screened. The original estimate of a population-wide reduction of $21-28 \%$ in breast cancer mortality from the national evaluation applied to the 50-69-year-old group. ${ }^{29}$ In the 70-74-year-old group, only about half of that benefit was indicated ${ }^{29}$, although case-control studies in Australia and the Netherlands suggest higher mortality reductions in women aged more than 70 years. ${ }^{27,30}$ In Australia, all women aged $40-49$ can access the national program but are not actively invited, so they need to initiate appointments themselves. The benefit from screening appears to have been similar in screened 45-59-year-old women to that in 50-69-year-old women in the national evaluation, but very small for 40-44-yearolds. ${ }^{29}$

The major issue around harms of breast screening centres on overdiagnosis. Overdiagnosis refers to cancer diagnosed by screening that would not have otherwise been diagnosed during a person's lifetime because it would never have caused symptoms. It is not a misdiagnosis or an error in diagnosis, and will occur to some extent with every screening program, and independently of screening in diagnostic environments.

Estimates of overdiagnosis vary widely in the 50-69-year-old group, from negligible to about $30 \%$ of detected cancers. ${ }^{31-34}$ The higher estimates were not because ductal carcinoma in situ (a type of noninvasive breast cancer) was included, but because different assumptions were made when estimating expected incidence rates without screening, and sometimes because lead-time effects in the screened population were not included. ${ }^{31,32}$ One study from Australia estimated overdiagnosis at between $23 \%$ and $30 \%$ of detected cancers $^{33}$, whereas another using a case-control design estimated overdiagnosis at closer to $8 \% .^{34}$

The issue with overdiagnosis is that it would lead to overtreatment - that is, treating someone who would never have developed symptoms from their cancer and yet would be exposed to the side-effects of the treatment. An important response to overdiagnosis is to fully inform women who are in the eligible age group that overdiagnosis can be a result of screening, so that they can consider it in their decision making alongside the potential mortality benefits of screening. Of course, there is always the dilemma of how population data translate to individual cases. There are also other adverse effects to consider, such as increased radiation exposure, although the risk of harm is considered extremely low. And, as with any screening and diagnostic test, adverse events can include both false-negative and false-positive results. ${ }^{27}$

It is encouraging that a study of British and Australian websites found that, in 2015-16, information about overdiagnosis was more widely available than previously. ${ }^{35}$ However, an Australian study found that experts still present information about screening according to their own views, ranging from "be screened" and "be screened and here's why", to "screening is available; please consider if it is right for you". ${ }^{36}$ Studies of the intention of women to be screened show little impact of information about overdiagnosis on their decisions. ${ }^{37,38}$

Younger women at high risk of cancer (e.g. BRCA1 carriers) can be screened with a magnetic resonance imaging (MRI) scan, which is otherwise not recommended for population screening because it is more sensitive but less specific, so results in more false positives. After the Australian Medical Services Advisory Committee confirmed the safety and efficacy of MRI with mammography for highrisk women, it was funded through Medicare in 2009 for asymptomatic high-risk women under 50 years of age. ${ }^{39}$

Women with a strong family history of breast cancer, or relatives of patients with known BRCA1 or BRCA2 mutations are tested for the presence of these mutations to ascertain their lifetime risk of developing breast cancer. An option for those who test positive is to have screening scans more regularly. There are now panels of genes that have been found to increase the diagnostic yield. With the increasing feasibility of using whole-genome sequencing across a population, the future of breast cancer screening may well include initially identifying at-risk individuals from their genetic profiles. ${ }^{40,41}$

\section{Screening for bowel cancer}

The most recent of the population cancer screening programs introduced into Australia is the NBCSP, introduced in 2006. This followed three pilot studies that demonstrated the efficacy of screening by distributing immunochemical faecal occult blood test (iFOBT) kits, which test stool samples to detect bleeding from abnormalities in the bowel. ${ }^{42}$ People who test positive are followed up with a colonoscopy. Effectively, if the iFOBT is positive, the likelihood of a positive follow-up result is 1240 times greater than if screening were conducted using the more sensitive colonoscopy as the primary screening tool (assuming that this would be an economically 
or logistically feasible test for 5 million asymptomatic people). ${ }^{43}$ Such tests will detect adenomas that are at risk of becoming cancerous and can be removed to prevent cancer, or early-stage cancers that are curable with surgery.

The target population for the NBCSP is the 50-74-year age range, and these people will receive bowel screening kits every 2 years. The program started with one-off screening at ages 55 and 65 years; 50 years was added in 2008, 60 years in 2013, and 70 and 74 years in 2015. More age groups will be added annually until the program rollout is completed in $2020 . .^{44-46}$

In 2013 and 2014, 37\% of the 2.2 million people in Australia invited to participate in screening returned their completed screening kits. The rates of participation were higher in women than men, and increased with age between 50 and 60 years and older. Participation rates were lower for people with lower socio-economic status and those in remote or very remote areas. Participation in 2009 was disrupted between May and November because of the discovery of faulty kits. In 2015,5715 people had to repeat the test because there had been more than 14 days' delay in processing samples. ${ }^{43,47}$

The positivity rate of iFOBT screening is $7 \%$ (males $8 \%$, females 6\%, 50-64-year age range 6\%, 65-69-year age range $9 \%$ ). Of these, $73 \%$ had the positive result followed up with a further diagnostic assessment (e.g. colonoscopy). In a 2016 report, the actual detection rate from 2014 was $0.7 \%$ with biopsy-proven colorectal cancer, $2.4 \%$ with suspected colorectal cancer, 14\% with biopsy-proven adenoma, and 23\% who were waiting for a polyp biopsy but were not suspected of having cancer. Importantly, approximately $60 \%$ of people had no adenoma or cancer. ${ }^{48}$ It is a cost-effective program, with an estimated cost of \$23 395 per life year gained if full participation could be achieved. ${ }^{49}$

An early analysis of patients with bowel cancer presenting in Australia between 2006 and 2008 showed the encouraging result that the number of people presenting with stage I disease if they had been screened was triple the number presenting with symptoms (40\% vs $14 \%) .{ }^{50} \mathrm{~A}$ conservative estimate of the lives to be saved by bowel screening in Australia was 500 each year, even with a low participation rate. ${ }^{51}$ The major adverse effect is the potential for morbidity such as perforation or bleeding from the follow-up colonoscopy, which is estimated to occur in $0.4 \%$ of procedures, with mortality of $0.004 \%$ in Australia. ${ }^{52}$

The NBCSP highlights issues seen in other Australian screening programs. Disadvantaged groups such as Aboriginal and Torres Strait Islander people, those who live in very remote areas and those from lower socio-economic groups have higher positivity rates and yet lower rates of, or more delayed, follow-up diagnostic assessment. ${ }^{48}$

The most striking aspect of the current bowel cancer screening program is the low participation rate, despite the proven potential to save lives with little risk from the initial screening iFOBT. Reasons include bowel cancer screening being the first population screening test that includes men; women have previous experience with population screening for breast and cervical cancer. The NBCSP is also the first population screening test that is self-administered, but does not sound like an attractive thing to do. However, we believe that the prolonged time (14 years) between the introduction of the initial tests in the first two age groups and the planned completion date makes it very hard to mount a public or indeed general practitioner education campaign, particularly as the kits are arriving sporadically. A new population screening test cannot be introduced instantly. BreastScreen was introduced over 4 years, and, with bowel cancer screening, the capacity for performing the follow-up colonoscopies had to be developed. However, in 2020 when bowel cancer screening kits will arrive every 2 years, public education should be easier, and a well-developed registry should help to address the issue of patients who test positive on the iFOBT but then do not present for follow-up.

The future of the program looks strong as a costeffective way of preventing deaths from colorectal cancer. Future strategies already being investigated include plasma DNA testing, but the performance of such tests (particularly the poor sensitivity in stage I cancer) currently makes DNA testing inappropriate to replace the iFOBT for primary screening. ${ }^{53}$

Another major challenge for the future is an increase in younger people presenting with bowel cancer. International evidence indicates that there is an increasing incidence of colorectal cancer in people under 50 years, but they may have a similar survival to the older patient groups. ${ }^{54,55}$ This does not suggest a lowering in the age of population screening, since only $2 \%$ or $8 \%$ of bowel cancer cases have been reported to be in this range. It does, however, indicate the need to identify younger people who are at high risk and test them earlier.

\section{Other cancers}

There has been discussion about possible population screening for other cancers. Prostate-specific antigen (PSA) testing has been suggested as a candidate for population screening; however, a 13-year follow-up of the European Randomized Study of Screening for Prostate Cancer showed that, for every 1000 men tested, 1.28 deaths were prevented, and 27 cancers were diagnosed to prevent 1 death. ${ }^{56}$ Considerable overdiagnosis and overtreatment can result from the PSA testing of asymptomatic men, because the test is not specific enough for prostate cancer. Guidelines released in 2014 by Cancer Council Australia and the Prostate Cancer Foundation of Australia suggest that men should be given the information to allow them to make an informed choice about whether to test, rather than suggesting population screening where the aim would be to test every asymptomatic man in the target age group. ${ }^{57}$

In the US, screening of a targeted population of people at high risk of lung cancer has been suggested. This is not population screening, but adults aged 55-80 with a smoking history of 30 pack-years who currently smoke or 
have quit within the past 15 years have been selected to be screened with low-dose computed tomography. ${ }^{58}$ This has resulted in a $20 \%$ reduction in mortality. However, there is a very high false-positive rate (96\%), which necessitates further investigations. Overdiagnosis is a problem, and the screening procedure is expensive. ${ }^{59}$ In 2015, the Australian Government Standing Committee on Screening did not support a lung cancer screening program. ${ }^{60}$

\section{Future}

In future, the three established screening programs should continue to demonstrate their impact on cancer mortality. The focus of research should be on how to increase informed participation of the general population and of distinct groups, such as Aboriginal and Torres Strait Islander people, people in lower socio-economic groups and people who live in very remote areas, who are not deriving full benefit from the current programs.

We should continue to see refinements in the accuracy of the screening tests, which will need to be integrated into the programs. Genomic testing should provide greater insight into identifying high-risk groups for screening in the future.

\section{Competing interests}

IO's institution received funding from companies Seqirus and Mundipharma for an educational session.

\section{Author contributions}

Both authors contributed to writing the manuscript and responding to the reviewers' comments.

\section{References}

1. Wilson JMG, Jungner G. Principles and practices of screening for disease. Geneva: World Health Organization; 1968 [cited 2017 Mar 21]. Available from: apps.who.int/iris/ handle/10665/37650?locale=en\&null

2. Australian Government Department of Health. Canberra: Department of Health; 2017. National Cervical Screening Program; 2017 [cited 2017 Mar2] [about 2 screens]. Avalable from: www.cancerscreening.gov.au/internet/ screening/publishing.nst/Content/cervical-screening-1

3. Australian Government Department of Health. Canberra: Department of Health; 2017. BreastSceen Australia; 2017 Jul 11 [cited 2017 March 21] [about 2 screens]. Available from: www.cancerscreening.gov.au/internet/ screening/publishing.nsf/Content/health-professionals-2

4. Australian Government Department of Health. Canberra: Department of Health; 2017. National Bowel Cancer Screening Program; 2017 Mar 1 [cited 2017 Mar 1] [about 2 screens]. Available from: www.cancerscreening.gov. au/internet/screening/publishing.nsf/Content/bowelscreening-1
5. Australian Institute of Health and Welfare. Australian incidence and mortality (ACIM). Canberra:

AlHW; 2017 [cited 2017 Mar 21]. Available from: aihw.gov.au/acim-books/

6. Australian Institute of Health and Welfare. Cervical screening in Australia 2011-2012. Canberra: AlHW; 2014 [cited 2017 Mar 21]. Available from: aihw.gov.au/ publication-detail/?id=60129546865

7. Moyer VA; U.S. Preventive Services Task Force. Screening for cervical cancer: U.S. Preventive Services Task Force recommendation statement. Ann Intern Med. 2012; 156(12):880-91.

8. Zhang X, Condon JR, Rumbold AR, Cunningham J, Roder DM. Estimating cancer incidence in Indigenous Australians. Aust N Z J Public Health. 2011;35(5):477-85.

9. Australian Institute of Health and Welfare. Cervical screening in Australia 2012-2013. Canberra: AlHW; 2015 [cited 2017 Jul 11]. Available from: www.aihw.gov.au/ publication-detail//id=60129550871

10. Whop LJ, Garvey G, Baade P, Cunningham J, Lokuge K, Brotherton JM, et al. The first comprehensive report on Indigenous Australian women's inequalities in cervical screening: a retrospective registry cohort study in Queensland, Australia (2000-2011). Cancer. 2016;122(10):1560-9.

11. Whop LJ, Baade P, Garvey G, Cunningham J, Brotherton JM, Lokuge K, et al. Cervical abnormalities are more common among Indigenous than other Australian women: a retrospective record-linkage study 2000-2001. PLoS One. 2016;11(4):e.0151473.

12. Aminisani N, Armstrong B, Canfell K. Uptake of liquidbased cytology as an adjunct to conventional cytology for cervical screening in NSW, Australia: a cross-sectional and population-based cohort analysis. BMC Public Health. 2013;13:1196.

13. Australian Government Department of Health. Canberra: Department of Health; 2017. Human Papillomavirus (HPV); 2017 Jan 17 [cited 2017 Jul 11] [about 3 screens]. Available from: health.gov.au/internet/immunise/publishing.nsf/ Content/immunise-hpv

14. International Agency for Research on Cancer Multicenter Cervical Cancer Study Group; Muñoz N, Bosch FX, de Sanjosé S, Herrero R, Castellsagué X, et al. Epidemiologic classification of human papillomavirus types associated with cervical cancer. N Engl J Med. 2003;348(6):518-27.

15. Garland SM, Ljaer SK, Muñoz N, Block SL, Brown DR, DiNubile MJ, et al. Impact and effectiveness of the quadrivalent human papillomavirus vaccine: a systematic review of 10 years of real-world experience. Clin Infect Dis. 2016;63(4):519-27.

16. Brotherton JML, Fridman M, May CL, Chappell G, Saville AM, Gertig DM. Early effect of the HPV vaccination programme on cervical abnormalities in Victoria, Australia: an ecological study. Lancet. 2011;377(9783):2085-92. 
17. Joura EA, Giuliano AR, Iversen OE, Bouchard C, Mao C, Mehlsen J, et al. A 9-valent vaccine against infection and intraepithelial neoplasia in women. N Engl J Med. 2015; 372(8):711-723.

18. Ronco G, Dillner J, Elfström KM, Tunesi S, Snijders PJ, Arbyn M, et al. Efficacy of HPV-based screening for prevention of invasive cervical cancer: follow-up of four European randomised controlled trials. Lancet 2014;383(9916):524-32

19. Compass. Future directions in cervical screening. VCS; 2017. Compass; 2017 [cited 2017 June 1] [about 2 screens]. Available from: www.compasstrial.org.au/

20. Australian Government Department of Health. Canberra: Department of Health; 2017. National Cervical Screening Program: overview of the renewal; 2017 May 17 [cited 2017 Mar 21] [about 3 screens]. Available from: www. cancerscreening.gov.au/internet/screening/publishing.nsf/ Content/overview-of-the-renewal

21. Australian Institute of Health and Welfare. Cancer incidence projections: Australia 2011 to 2020. Canberra: AlHW; 2012 [cited 2017 Jul 11]. Available from: www.aihw.gov.au/ publication-detail/?id=10737421461

22. Australian Institute of Health and Welfare. BreastScreen Australia monitoring report 2010-2011. Canberra: AlHW; 2013 [cited 2017 Mar 21]. Available from: www.aihw.gov.au/ publication-detail/?id=60129544882

23. Roder D. Impact of population screening programs on cancer outcomes. Cancer Forum. 2012;36(1):5-10.

24. Berry DA, Cronin KAS, Plevritis SK, Fryback DG, Clarke L, Zelen M, et al. Effect of screening and adjuvant therapy on mortality from breast cancer. N Engl $\mathrm{J}$ Med. 2005;353(17):1784-92.

25. Morrell S, Taylor R, Roder D, Dobson A. Mammography screening and breast cancer mortality in Australia: an aggregate cohort study. J Med Screen. 2012;19(1):26-34.

26. Taylor R, Morrell S, Estoesta J, Brassil A. Mammography screening and breast cancer mortality in New South Wales. Cancer Causes Control. 2004;15(6):543-50.

27. Roder D, Houssami N, Farshid G, Gill G, Luke C, Downey $P$, et al. Population screening and intensity of screening are associated with reduced breast cancer mortality: evidence of efficacy of mammography screening in Australia. Breast Cancer Res Treat. 2008;108(3):409-16.

28. Nickson C, Mason KE, English DR, Kavanagh AM. Mammographic screening and breast cancer mortality: a case-control study and meta-analysis. Cancer Epidemiol Biomarkers Prev. 2012;21(9):1479-88.

29. Australian Government Department of Health. Canberra: Department of Health; 2017. BreastScreen Australia; 2014 Oct 24. Program evaluation. BreastScreen Australia final report, 2009 [cited 2017 Mar 21] [about 13 screens]. Available from: cancerscreening.gov.au/internet/screening/ publishing.nsf/Content/programme-evaluation
30. Otto SJ, Fracheboud J, Verbeek AL, Boer R, Reijerink-Verheij JC, Otten JD, et al. Mammography screening and risk of breast cancer death: a population-based case-control study. Cancer Epidemiol Biomarkers Prev. 2012;21(1):66-73.

31. Njor SH, Olsen AH, Blichert-Toft M, Schwartz W, Vejborg I, Lynge E. Overdiagnosis in screening mammography in Denmark: population based cohort study. BMJ. 2013;346:f1064.

32. Falk RS, Hofvind S, Skaane P, Haldorsen T. Overdiagnosis among women attending a populationbased mammography screening program. Int $\mathrm{J}$ Cancer. 2013;133(3):705-12.

33. Morrell S, Barratt A, Irwig L, HowardK, Biesheuvel C, Armstrong B. Estimates of overdiagnosis of invasive breast cancer associated with screening mammography. Cancer Causes Control. 2010;21(2):275-82.

34. Beckmann K, Duffy SW, Lynch J, Hiller J, Farshid G, Roder D. Estimates of over-diagnosis of breast cancer due to population-based mammography screening in South Australia after adjustment for lead time effects. J Med Screen. 2015;22(3):127-35.

35. Ghanouni A, Meisel SF, Hersch J, Waller J, Wardle J, Renzi C. Information on "overdiagnosis" in breast screening on prominent United Kingdom and Australia-oriented health websites. PLoS One. 2016;11(3):e0152279.

36. Parker LM, Rychetnik L, Carter SM. The role of communication in breast cancer screening: a qualitative study with Australian experts. BMC Cancer. 2015;15:741.

37. Hersch J, Jansen J, Barratt A, Irwig L, Houssami N, Howard K, et al. Women's views on overdiagnosis in breast cancer screening: a qualitative study. BMJ. 2013;346:f158.

38. Waller J, Douglas E, Whitaker KL, Wardle J. Women's responses to information about overdiagnosis in the UK breast cancer screening programme: a qualitative study. BMJ Open. 2013;3(4):pii:e002703

39. Medical Services Advisory Committee. Breast magnetic resonance imaging: assessment report. MSAC application 1098. Canberra: Commonwealth of Australia; 2007 [cited 2017 Mar 21]. Available from: www.msac.gov.au/internet/ msac/publishing.nsf/Content/A5DC00F5BABA24A9CA258 01000123B45/\$File/1098-Assessment-Report.pdf

40. Ahmadloo S, Nakaoka H, Hayano T Hosomichi K, You H, Utsuno E, et al. Rapid and cost-effective high-throughput sequencing for identification of germline mutations of BRCA1 and BRCA2. J Hum Genet. 2017;62(5):561-7.

41. Vysotskaia VS, Hogan GJ, Gould GM, Wang X, Robertson AD, Haas KR, et al. Development and validation of a 36-gene sequencing assay for hereditary cancer risk assessment. PeerJ. 2017;5:e3046.

42. Mandel JS, Church TR, Ederer F, Bond JH. Colorectal cancer mortality: effectiveness of biennial screening for fecal occult blood. J Natl Cancer Inst. 1999;91(5):434-7. 
43. Australian Government Department of Health. Canberra: Commonwealth of Australia. National Bowel Cancer Screening Program: overview of the NBCSP; 2017 Jul 12 [cited 2017 Mar 21]; [about 4 screens]. Available from: www.cancerscreening.gov.au/internet/screening/ publishing.nsf/Content/rev-nbcs-prog-pt2 overview

44. Commonwealth of Australia. Portfolio budget statements 2008-09: budget related paper no. 1.10. Health and ageing portfolio. Canberra: Commonwealth of Australia; 2008 [cited 2017 Mar 21]. Available from: www.health.gov. au/internet/budget/publishing.nsf/Content/2008-2009_ Health_PBS_sup4/\$File/Health\%20and\%20Ageing\%20 Portfolio\%20Budget\%20Statements\%202008-09.pdf

45. Australian Government Department of Health. Canberra: Commonwealth of Australia. Australian Government 2012-13 health and ageing portfolio budget statements; 2012 May 8 [cited 2017 Mar 21]; [about 4 screens]. Available from: www.health.gov.au/internet/budget/ publishing.nsf/Content/2012-2013_Health_PBS

46. Australian Government Department of Health. Canberra: Commonwealth of Australia. More bowel cancer screening will save lives; 2014 May 13 [cited 2017 Mar 21]; [about 2 screens]. Available from: www.health.gov.au/internet/ budget/publishing.nsf/content/budget2014-hmedia09.htm

47. Australian Government Department of Health. Canberra: Commonwealth of Australia. National Bowel Screening Program re-issuing kits to some participants as a precautionary measure; 2016 Feb 15 [cited 2017 Jul 12]; [about 2 screens]. Available from: www.cancerscreening. gov.au/internet/screening/publishing.nsf/Content/bowelkit-reissue

48. Australian Institute of Health and Welfare. National Bowel Cancer Screening Program: monitoring report 2016. Canberra: AlHW; 2016. Available from: www.aihw.gov.au/ WorkArea/DownloadAsset.aspx?id=60129555864

49. Tran B, Keating CL, Ananda SS, Kosmider S, Jones I, Croxford M, et al. Preliminary analysis of the cost-effectiveness of the National Bowel Cancer Screening Program: demonstrating the potential value of comprehensive real world data. Intern Med J. 2012;42(7):794-800.

50. Ananda SS, McLaughlin SJ, Chen F, Hayes IP, Hunter AA, Skinner IJ, et al. Initial impact of Australia's National Bowel Cancer Screening Program. Med J Aust. 2009;191(7):378-81.

51. Pignone MP, Flitcroft KL, Howard K, Trevena LJ, Salkeld GP, St John DJ. Costs and cost-effectiveness of full implementation of a biennial faecal occult blood test screening program for bowel cancer in Australia. Med J Aust. 2011;194(4):180-5.
52. Viiala CH, Zimmerman M, Cullen DJ, Hoffman NE. Complication rates of colonoscopy in an Australian teaching hospital environment. Intern Med J. 2003;33(8):355-9.

53. Young GP, Pedersen SK, Dekker E, Cole SR, Osborne JM, Symonds El, et al. Evaluation of a 2-gene (IKZF1 and BCAT1) DNA blood test for detection of colorectal cancer. In: AASLD, AGA, ASGE, SSAT. Digestive Disease Week. 2014 May 3-6; Chicago; 2014.

54. Austin H, Henley SJ, King J, Richardson LC, Eheman C. Changes in colorectal cancer incidence rates in young and older adults in the United States: what does it tell us about screening. Cancer Causes Control. 2014;25(2):191-201.

55. Vatandoust S, Price TJ, Ullah S, Roy AC, Beeke C, Young JP, et al. Metastatic colorectal cancer in young adults: a study from the South Australian population-based registry. Clin Colorectal Cancer. 2016;15(1):32-6.

56. Schroder FH, Hugosson J, Roobol MJ, Tammela TL, Zappa M, Nelen V, et al. Screening and prostate cancer mortality: results of the European Randomised Study of Screening for Prostate Cancer (ERSPC) at 13 years of follow-up. Lancet. 2014;384(9959):2027-35.

57. Prostate Cancer Foundation of Australia and Cancer Council Australia. PSA testing and early management of test-detected prostate cancer: clinical practice guidelines. Sydney: Prostate Cancer Foundation of Australia and Cancer Council Australia; 2016 [cited 2017 Mar 21]. Available from: wiki.cancer.org.au/australiawiki/ images/1/1b/PSA_Testing_and_Early_Management_of_ Test-detected_Prostate_Cancer_-_Clinical_practice_ guidelines_-_Nov15.pdf

58. Moyer VA; U.S. Preventive Services Task Force. Screening for lung cancer: U.S. Preventive Services Task Force recommendation statement. Ann Intern Med. 2014;160(5):330-8.

59. National Lung Screening Trial Research Team, Aberle DR, Adams AM, Berg CD, Black WC, Clapp JD, Fagerstrom RM, et al. Reduced lung-cancer mortality with low-dose computed tomographic screening. N Engl J Med. 2011;365(5):395-409.

60. Australian Government Standing Committee on Screening. Position statement: lung cancer screening. Canberra: Commonwealth of Australia; 2015 [cited 2017 Mar 21]. Available from: www.cancerscreening.gov.au/internet/ screening/publishing.nsf/Content/EA40B7C67280E5C8 CA257CEE00012DA1/\$File/Position\%20Statement-\%20 Lung\%20Cancer\%20Screening\%20using\%20LowDose\%20Computed\%20Tomography.pdf

\section{Copyright: (c) (i) (2)}

(C) 2017 Olver and Roder. This article is licensed under the Creative Commons Attribution-NonCommercial-ShareAlike 4.0 International Licence, which allows others to redistribute, adapt and share this work non-commercially provided they attribute the work and any adapted version of it is distributed under the same Creative Commons licence terms. See: www.creativecommons.org/licenses/by-nc-sa/4.0/ 